\title{
PREPARATION AND CHARACTERIZATION OF ENTERIC COATED MUCOADHESIVE TABLET OF CAPTOPRIL
}

\author{
SD College of Pharmacy Barnala, Punjab, India- 148101 \\ *Corresponding Author's E-mail: kapil.sharma906@gmail.com
}

Sharma Kapil dev*, Goswami Dhruba Sankar, Seth Mona, Kashyap Swati, Daliwal Hardeep and Uppal Nidhi

\begin{abstract}
Delayed sustained release formulation is to retard release of the drug form the stomach and release in the intestinal $\mathrm{pH}$. Captopril is recommended as first choice of drug. Attacks of the myocardial infarction are generally in the early morning or night. Captopril is showing less bioavailability in presence of food. With enteric coating problem should be solved out. It also minimizes the gastric irritation of the captopril. Captopril is widely used for the arterial hypertension. It also used for myocardial infarction and in diabetic nephropathy. The drug dose is taken three times daily, which may give poor patients compliance. In the present investigation, an attempt was made to decrease dosing frequency by prepare a mucoadhesive tablets using various polymers such as HPMC K4M, bael gum and chitosan. Eudragit RL100 used as enteric coating polymer. Formulations friability, drug content, surface $\mathrm{pH}$, wash off test, mucoadhesive strength and dissolution study. The results of friability tests carried out for all the formulations are within the official limit and acceptable. According to wash off test the formulation containing bael gum showing better results. All the formulation was showing better swelling property. F4 (formulation containing bael gum) was showing best mucoadhesive strength among all the formulations. In in-vitro drug release study formulation (F4) containing bael gum showing better control release among all the formulations i.e. $86.488 \%$ in 12 hrs.
\end{abstract}

Keywords: Enteric coated, mucoadhesive tablet, captopril, HPMC K4M, bael gum

\section{INTRODUCTION}

Sustained release drug delivery systems are designed to achieve a prolonged therapeutic effect by continuously releasing medication over an extended period of time. The goal in designing oral sustained or controlled delivery systems is to reduce the frequency of the dosing or to increase effectiveness of the drug by localizing at the site of action, reducing the dose required or provide uniform drug delivery, thereby also improving patient compliance. Sustained release dosage forms provide a better control of plasma drug levels, less dosage frequency, less side effect, increased efficacy and constant delivery. ${ }^{1}$

Enteric term refers to intestine. ${ }^{2}$ The most common type of modified release coating is the enteric coat, which is designed to prevent release of the drug substance in the stomach because the drug is either irritant to the gastric mucosa or it is unstable in gastric juice. Film coating can also be used to delay the release of drugs. ${ }^{3}$

Captopril is used therapeutically as an anti-hypertensive agent. Captopril is widely used for the arterial hypertension. It acts as a potent and specific inhibitor of angiotensin converting enzyme. It is used in the management of hypertension, in heart failure, following myocardial infarction and in diabetic nephropathy. It seems to be one of the most widely used drug for hypertension and heart problems. ${ }^{4}$

In the present investigation, an attempt was made to decrease dosing frequency. Captopril is showing less bioavailability in presence of food. With enteric coating problem should be solved out.

\section{MATERIAL AND METHOD}

Captopril was purchased from wockhardt Ltd. Aurangabad. HPMC K4M, talc, lactose, magnesium stearate, di-sodium hydrogen orthophosphate and sodium chloride was purchased from Central drug house (P) LTD New Delhi. Sodium alginate was procured from himedia lab. Pvt Ltd. Mumbai. Eudragit RL 100 was purchased from balaji drugs, Gujarat.

\section{Extraction of polymer from Aegle marmelos ${ }^{5}$}

In this method, $250 \mathrm{gm}$ edible fruits of Aegle marmelos were soaked in double distilled water and boiled for $5 \mathrm{hrs}$ in a water bath until slurry was formed. The slurry was cooled and kept in refrigerator overnight so that most of the undissolved portion was settled out. The upper clear solution was decanted off and centrifuged at $500 \mathrm{rpm} 20$ mins. The supernatant was concentrated at $60^{\circ} \mathrm{C}$ on a water bath until the volume reduced to one third of its original volume. Solution was cooled down to the room temperature and was poured into thrice the volume of acetone by continuous starring. The precipitate was washed repeatedly with acetone and dried at $50^{\circ} \mathrm{C}$ under vacuum. The dried material was powdered and kept in a desiccator.

\section{Physical characteristics of granules before compression $^{6}$}

The angle of repose can be determined by fixed funnel method. The bulk density and tapped density were determined by the cylinder method.

Compressibility index and hausner ratio was calculated by using following formula:

$$
\begin{aligned}
\text { Compressability index } & =\frac{(\mathrm{Vo}-\mathrm{Vf})}{\mathrm{Vo}} * 100 \\
\text { Hausner Ratio } & =\frac{\mathrm{V} 0}{\underline{\mathrm{Vf}}}
\end{aligned}
$$

Were $\mathrm{V} 0=$ initial volume, $\mathrm{Vf}=$ tapped volume 


\section{Preparation of mucoadhesive tablet $^{7}$}

Mucoadhesive tablets each containing $50 \mathrm{mg}$ of captopril were prepared by conventional wet granulation method employing HPMC K4M, bael gum and chitosan as mucoadhesive materials as shown in the formulae given in table No. 1. A batch of 60 tablets was prepared in each case a blend of $3 \mathrm{gm}$ of captopril with required amount of polymers. Which were then granulated along with a solvent blend of water and ethanol (1:1). Firstly required amount of drug and polymer were taken in a mortar and pestle for the trituration. Then the solvent was added drop wise with continuous stirring until the wet mass was formed. Then the wet masses were passed through 12 mesh sieve and wet granules were dried at $60^{\circ} \mathrm{C}$ for $4 \mathrm{hrs}$. The dried granules ( 20 mesh) after blending with talc $(0.5$ $\%$ ) and magnesium stearate $(0.5 \%)$ in a laboratory cube blender for 5 mins. Then granules were compressed into $300 \mathrm{mg}$ tablets of hardness $6-7 \mathrm{~kg} / \mathrm{cm}^{2}$ on a tablet compression machine using $10 \mathrm{~mm}$ biconcave shaped punches. Prepared tablets were used for the evaluation parameters.

Table 1: Composition of the various formulations

\begin{tabular}{|l|l|l|l|l|l|l|l|l|}
\hline $\begin{array}{l}\text { Formulation } \\
\text { code }\end{array}$ & $\begin{array}{l}\text { Captopril } \\
(\mathbf{m g})\end{array}$ & $\begin{array}{l}\text { HPMC K4M } \\
(\mathbf{m g})\end{array}$ & $\begin{array}{l}\text { Bael gum } \\
(\mathbf{m g})\end{array}$ & $\begin{array}{l}\text { Chitosan } \\
(\mathbf{m g})\end{array}$ & $\begin{array}{l}\text { Lactose } \\
(\mathbf{m g})\end{array}$ & $\begin{array}{l}\text { Talc } \\
(\mathbf{\%})\end{array}$ & $\begin{array}{l}\text { Mg. } \\
\text { stearate } \\
(\%)\end{array}$ & $\begin{array}{l}\text { Total } \\
\mathbf{w t} .\end{array}$ \\
\hline F1 & 50 & 200 & ------- & ------- & 50 & 0.5 & 0.5 & 300 \\
\hline F2 & 50 & 100 & 100 & ------- & 50 & 0.5 & 0.5 & 300 \\
\hline F3 & 50 & 100 & ------ & 100 & 50 & 0.5 & 0.5 & 300 \\
\hline F4 & 50 & ------- & 200 & ------- & 50 & 0.5 & 0.5 & 300 \\
\hline F5 & 50 & ------- & 100 & 100 & 50 & 0.5 & 0.5 & 300 \\
\hline F6 & 50 & ------ & ------- & 200 & 50 & 0.5 & 0.5 & 300 \\
\hline
\end{tabular}

\section{Coating procedure of mucoadhesive tablet $^{7}$}

\section{Preparation of film coating solution}

A basic film coating solution as shown in table no. 2 was prepared. In a $500 \mathrm{ml}$ clean beaker about $100 \mathrm{ml}$ of methanol was measured and the required amount of polymer eudragit RL100 was added and allowed to soak overnight. Next day morning, filter solution through muslin cloth and kept under a stirrer for 5 mins to get a uniform dispersion of the polymer solution. Other ingredients such as plasticizers, opacifier, colour etc. were added by mixing to get the coating liquid.

Table 2: Composition of coating solution

\begin{tabular}{|l|l|l|}
\hline S. No. & Ingredients & Amount \\
\hline 1 & Eudragit RL100 & $7.5 \%$ \\
\hline 2 & PEG 400 & $0.8 \%$ \\
\hline 3 & Titanium dioxide & $3.1 \%$ \\
\hline 4 & Methanol & $100 \mathrm{ml}$ \\
\hline 5 & Colour & $0.1 \%$ \\
\hline
\end{tabular}

\section{Coating procedure:}

Mucoadhesive tablets of captopril taken in a perforated tray. The coating solution was filled into the laboratory sprayer. Then the coating solution was sprayed over the tablets from certain distance by controlling the spray rate. Constant temperature was maintained, while the tray was shaken manually. The solution was sprayed intermittently allowing the solvent to evaporate.

\section{Evaluation of the mucoadhesive tablet:}

\section{Thickness and diameter: ${ }^{8}$}

The thickness and diameter of mucoadhesive tablets was determined using vernier calliper. Ten individual tablets from each batch were used and the results averaged.

\section{Weight variation:}

Weight variation was performed for 20 tablets from each batch using an electronic balance and average values were calculated.

\section{Friability: ${ }^{7}$}

The friability test was done using Roche's friabilator. Ten tablets were selected and weighed individually. Then the friability test was carried out at $25 \mathrm{rpm}$ for 4 mins. These tablets were then again weighed and percentage loss in weight was calculated. The friability $(\mathrm{F})$ is given by the formula:

$$
\mathrm{F}=(1-\mathrm{Wo} / \mathrm{W}) 100
$$

Where Wo is weight of tablets before test and $\mathrm{W}$ is weight of the tablets after test.

\section{Hardness: 8}

Hardness was conducted for 3 tablets from each batch using Monsanto hardness tester and average values were calculated

\section{Surface pH Study:}

The bioadhesive tablet was allowed to swell by keeping it in contact with $1 \mathrm{~mL}$ of distilled water for $2 \mathrm{hrs}$ at room temperature. The $\mathrm{pH}$ was measured by bringing the $\mathrm{pH}$ meter electrode, in contact with the surface of the tablet and allowing it to equilibrate for $1 \mathrm{~min}$.

Drug Content: 
Three tablets from each batch were taken in separate 100 $\mathrm{mL}$ volumetric flaks containing $100 \mathrm{~mL}$ of $\mathrm{pH} 7.4$ phosphate buffer and were kept for $24 \mathrm{hrs}$ under constant stirring. The solutions were then filtered, diluted suitably and analyzed at $212 \mathrm{~nm}$ using UV-spectrophotometer.

The average of three tablets was taken as the content of drug in one tablet unit.

\section{Swelling index: ${ }^{10}$}

Swelling of tablet excipients particles involves the absorption of a liquid resulting in an increase in weight and volume. Liquid uptake by the particle may be due to saturation of capillary spaces within the particles or hydration of macromolecule. The liquid enters the particles through pores and bind to large molecule, breaking the hydrogen bond and resulting in the swelling of particle. The extent of swelling can be measured in terms of \%weight gain by the tablet. For each formulation batch, one tablet was weighed and placed in a beaker containing $200 \mathrm{ml}$ of phosphate buffer media $\mathrm{pH} \mathrm{7.4.}$ After each interval the tablet was removed from beaker and weighed again up to $9 \mathrm{hrs}$. The swelling index was calculated using following formula.

$$
\text { Swelling index (S.I.) }=(\text { Wt-Wo }) / \text { Wo } \times 100
$$

Where, S.I. = Swelling index

$\mathrm{Wt}=$ Weight of tablet at time $\mathrm{t}$

Wo $=$ Weight of tablet before placing in the beaker

\section{Wash off test: ${ }^{7}$}

The mucoadhesive properties of the tablets were evaluated by an in-vitro adhesion testing method known as wash off method. Pieces of intestinal mucosa were mounted on to glass slides were connected with suitable support. About 2 tablets attached on to the slide and the support was hung on to the arm of a USP tablet disintegrating test machine. By operating the disintegrating test machine was given a slow regular up and down movement in the test fluid (phosphate buffer $\mathrm{pH} 7.4$ ) at $37^{\circ} \mathrm{C}$ temperatures. At the time of detachment of both tablets was noted down.

\section{Mucoadhesive strength: ${ }^{10}$}

Mucoadhesive strength of the tablets was measured on the modified physical balance. The apparatus consist of a modified double beam physical balance in which the right pan has been replaced by a glass slide with copper wire and additional weight, to make the right side weight equal with left side pan. A taflone block of $3.8 \mathrm{~cm}$ diameter and $2 \mathrm{~cm}$ height was fabricated with an upward portion of 2 $\mathrm{cm}$ height and $1.5 \mathrm{~cm}$ diameter on one side. This was kept in beaker filled with phosphate buffer $\mathrm{pH} 7.4$, which was then placed below right side of the balance. Goat intestinal mucosa was used as a model membrane and phosphate buffer pH 7.4 was used as moistening fluid. The goat intestinal mucosa was obtained from local slaughter house and kept in a Krebs buffer during transportation. The underlying mucous membrane was separated using surgical blade and wash thoroughly with phosphate buffer $\mathrm{pH}$ 7.4. It was then tied over the protrusion in the teflon block using a thread. The block was then kept in glass beaker. The beaker was filled with phosphate buffer $\mathrm{pH} 7.4$ up to the upper surface of the (c) 2011, JDDT. All Rights Reserved goat intestinal mucosa to maintain intestinal mucosa viability during the experiments. The one side of the tablet was attached to the glass slide of the right arm of the balance and then the beaker was raised slowly until contact between goat intestinal mucosa and mucoadhesive tablet was established. A preload of $10 \mathrm{mg}$ was placed on the slide for 15 mins (preload time) to established adhesion bonding between mucoadhesive tablet and goat intestinal mucosa. The preload and preload time were kept constant for all formulations. After the completion of preload time, preload was removed from the glass slide and water was then added in the plastic bottle in left side arm by peristaltic pump at a constant rate of 100 drops per min. The addition of water was stopped when mucoadhesive tablet was detached from the goat intestinal mucosa. The weight of water required to detach mucoadhesive tablet from goat intestinal mucosa was noted as mucoadhesive strength in grams. Force of adhesion was calculated from this test by using the following formula.

$$
\text { Force of adhesion }(\mathrm{N})=\frac{\text { Mucoadhesive strength }}{1000} \times \mathbf{9} .81
$$

\section{In-vitro drug release studies of enteric coated tablet: ${ }^{6}$}

The release rates of prepared enteric coated mucoadhesive tablets of Captopril were studied using the (USP II) rotating paddle method under sink conditions at $37 \pm 0.5^{\circ} \mathrm{c}$ and $50 \mathrm{rpm}$. The tablets were placed in the basket and tested for drug release for $2 \mathrm{hrs}$ in $0.1(\mathrm{~N}) \mathrm{HCl}$ solution and tested for drug release for $1 \mathrm{hr}$ in $\mathrm{pH} 6.5$ and 7.8 phosphate buffer solution upto $12 \mathrm{hrs}$.

\section{Kinetics of Drug Release: ${ }^{12}$}

\section{Zero order models:}

Drug dissolution from dosage forms that do not disaggregate and release the drug slowly can be represented by the equation:

$$
Q_{\mathrm{t}}-\mathbf{Q}_{0}=-\mathbf{K}_{0} \mathrm{t}
$$

Rearrangement of equation (1) yields:

$$
Q_{t}=Q_{0}-K_{0} t
$$

Whereas $\mathrm{Q}_{\mathrm{t}}$ is the amount of drug dissolved in time $t$,

$\mathrm{Q}_{0}$ is the initial amount of drug in the solution (most times, $\mathrm{Q}_{0}=0$ ) and $\mathrm{K}_{0}$ is the zero order release constant expressed in units of concentration/time.

First order model:

The release of the drug which followed first order kinetics can be expressed by the equation:

$$
\mathbf{d c} / \mathbf{d t}=-\mathbf{k c}
$$

Where $\mathrm{k}$ is first order rate constant expressed in units of time $^{-1 .}$

Equation (3) can be expressed as:

$$
\log C=\log C_{0}-k_{t} / 2.303
$$

Where $\mathrm{C}_{0}$ is the initial concentration of drug, $\mathrm{k}$ is the first order rate constant, and $\mathrm{t}$ is the time. The data obtained are plotted as log cumulative percentage of drug remaining vs. time which would yield a straight line with a slope of $-\mathrm{k} / 2.303$. 
Higuchi model:

The first example of a mathematical model aimed to describe drug release from a matrix system was proposed by Huguchi in 1961 .

$$
\mathbf{f}_{\mathrm{t}}=\mathbf{Q}=\mathbf{A} \sqrt{ } \mathbf{D}\left(\mathbf{2 C}-\mathbf{C}_{\mathrm{s}}\right) \mathbf{C}_{\mathrm{s}} \mathbf{t}
$$

Where $\mathrm{Q}$ is the amount of drug released in time $\mathrm{t}$ per unit area $\mathrm{A}, \mathrm{C}$ is the drug initial concentration, $\mathrm{C}_{\mathrm{s}}$ is the drug solubility in the matrix media and $\mathrm{D}$ is the diffusivity of the drug molecules (diffusion coefficient) in the matrix substance.
Korsmeyer Peppas model:

Korsmeyer et al., (1983) derived a simple relationship which described drug release from a polymeric system equation. To find out the mechanism of drug release, drug release data were fitted in Korsmeyer Peppas model.

$$
M t / M_{\infty}=K t_{n}
$$

Where $\mathrm{Mt} / \mathrm{M}_{\infty}$ are a fraction of drug released at time $\mathrm{t}, \mathrm{k}$ is the release rate constant and $\mathrm{n}$ is the release exponent.

\section{RESULT AND DISCUSSION:}

Result:

Table 3: Evaluation of granules

\begin{tabular}{|c|c|c|c|c|c|c|}
\hline $\begin{array}{c}\text { Formulation } \\
\text { code }\end{array}$ & $\begin{array}{c}\text { Angle of repose } \\
\mathbf{(}^{\mathbf{9}}\end{array}$ & $\begin{array}{c}\text { Bulk density } \\
\left(\mathbf{g m} / \mathbf{c m}^{\mathbf{3}}\right)\end{array}$ & $\begin{array}{c}\text { Tapped density } \\
\left(\mathbf{g m} / \mathbf{c m}^{\mathbf{3}}\right)\end{array}$ & $\begin{array}{c}\text { Carr's ratio } \\
(\mathbf{\%})\end{array}$ & $\begin{array}{c}\text { Hausner's } \\
\text { ratio }\end{array}$ & $\begin{array}{c}\text { Total porosity } \\
(\mathbf{\%})\end{array}$ \\
\hline F1 & 22.83 & 0.51 & 0.58 & 12.06 & 1.13 & 11.39 \\
\hline F2 & 21.29 & 0.58 & 0.63 & 7.93 & 1.08 & 8.64 \\
\hline F3 & 23.45 & 0.59 & 0.64 & 7.81 & 1.08 & 12.50 \\
\hline F4 & 20.32 & 0.51 & 0.58 & 12.06 & 1.13 & 8.75 \\
\hline F5 & 23.41 & 0.51 & 0.58 & 12.06 & 1.13 & 13.41 \\
\hline F6 & 25.78 & 0.52 & 0.59 & 11.86 & 1.13 & 22.22 \\
\hline
\end{tabular}

Table 4: Evaluation of mucoadhesive tablet

\begin{tabular}{|c|c|c|c|c|c|c|c|}
\hline $\begin{array}{c}\text { Formulation } \\
\text { code }\end{array}$ & $\begin{array}{c}\text { Thickness } \\
(\mathbf{m m})\end{array}$ & $\begin{array}{c}\text { Diameter } \\
\mathbf{( \mathbf { m m } )}\end{array}$ & $\begin{array}{c}\text { Hardness } \\
\left(\mathbf{k g} / \mathbf{c m}^{\mathbf{2}}\right)\end{array}$ & $\begin{array}{c}\text { Weight } \\
\text { variation } \\
\mathbf{( \% )}\end{array}$ & $\begin{array}{c}\text { Friability } \\
(\boldsymbol{\%})\end{array}$ & $\begin{array}{c}\text { Drug } \\
\mathbf{c o n t e n t} \\
(\boldsymbol{\%})\end{array}$ & $\begin{array}{c}\text { Surface } \\
\mathbf{p H}\end{array}$ \\
\hline F1 & 5.4 & 9.6 & 6.9 & 0.020 & 0.100033 & 94.347 & 7.1 \\
\hline F2 & 5.5 & 9.5 & 6.7 & -0.006 & 0.100167 & 99.130 & 7.1 \\
\hline F3 & 5.6 & 9.6 & 6.4 & 0.009 & 0.100127 & 97.391 & 7.0 \\
\hline F4 & 5.4 & 9.6 & 6.5 & 0.016 & 0.033344 & 93.043 & 6.9 \\
\hline F5 & 5.5 & 9.6 & 6.5 & 0.028 & 0.100033 & 94.782 & 7.0 \\
\hline F6 & 5.7 & 9.4 & 6.6 & -0.005 & 0.100067 & 97.391 & 7.1 \\
\hline
\end{tabular}

Table 5: Wash off test

\begin{tabular}{|c|c|c|c|}
\hline Formulation code & Sl. No. of tablet & Detachment time (mins) & $\begin{array}{c}\text { Average detachment time } \\
\text { (mins) }\end{array}$ \\
\hline F1 & 1 & 421 & 416 \\
\hline F2 & 2 & 411 & 428 \\
\hline F3 & 1 & 432 & 390 \\
\hline F4 & 1 & 424 & 452 \\
\hline F5 & 2 & 372 & \multirow{2}{*}{4} \\
\hline F6 & 1 & 408 & 401 \\
\hline
\end{tabular}




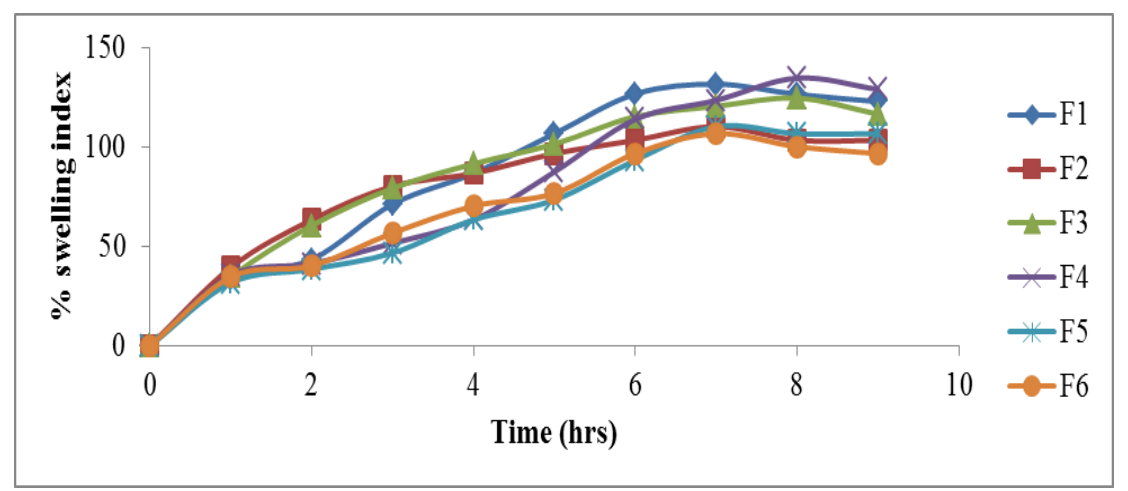

Figure 1: Comparative \%swelling index of formulation F1 to F6.

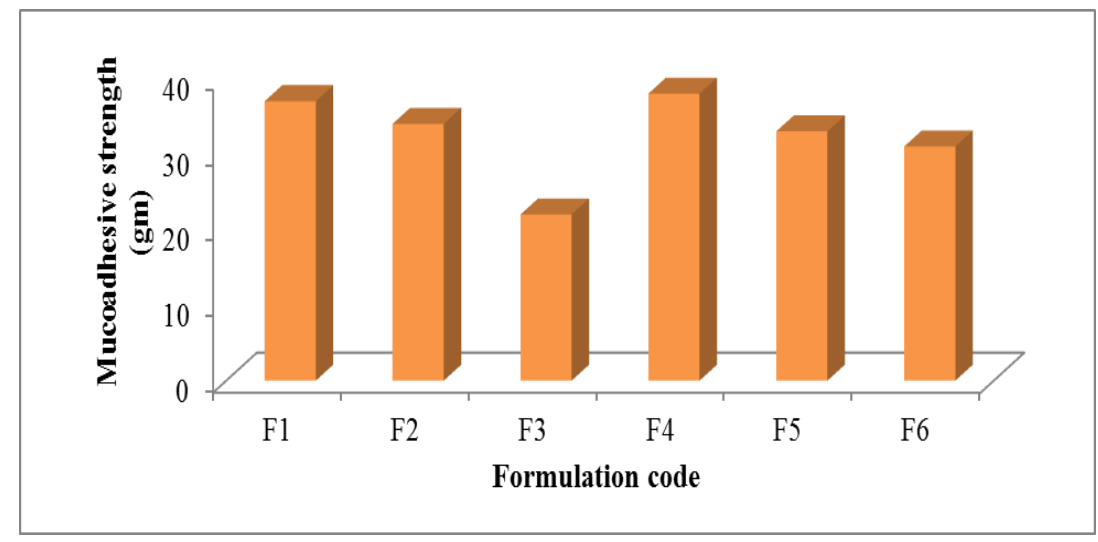

Figure 2: Comparative mucoadhesive strength of various formulations.

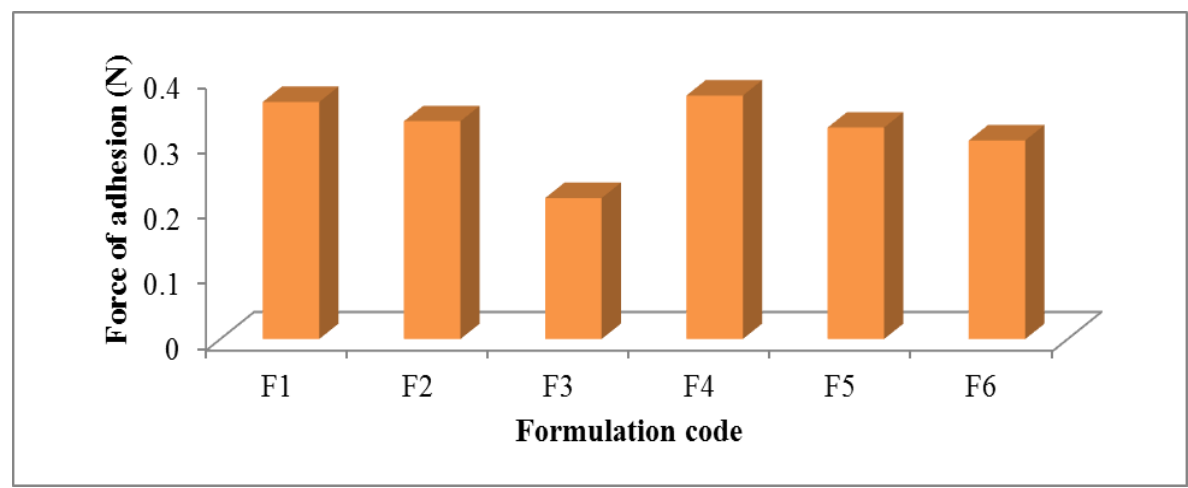

Figure 3: Comparative force of adhesion of various formulations.

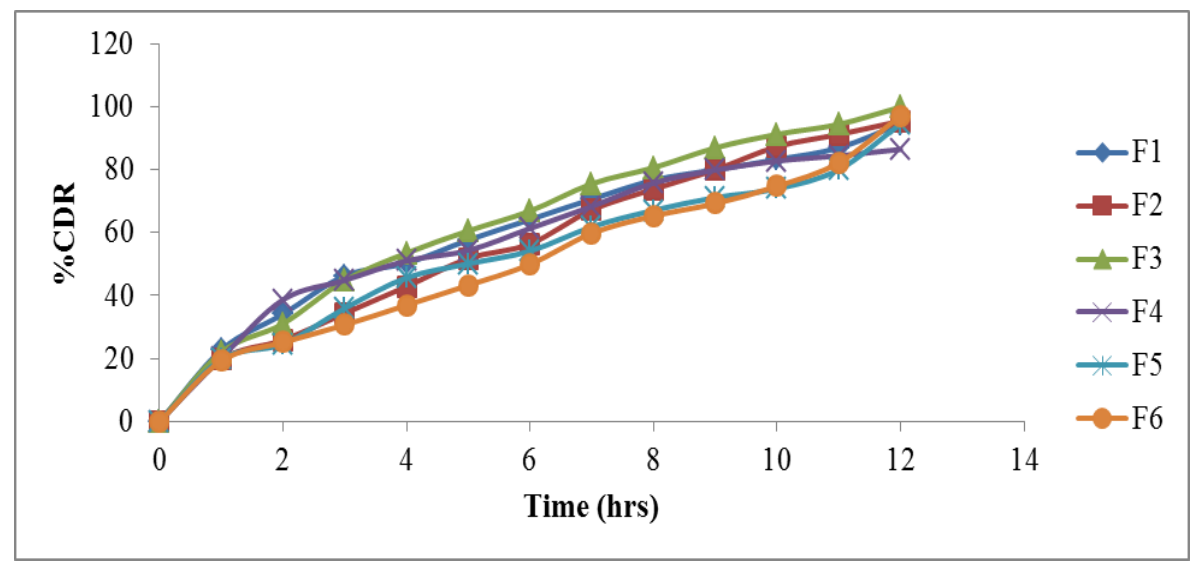

Figure 4: Comparative \%cumulative drug release of various formulations. 
Release kinetics of formulation containing bael gum (F4):

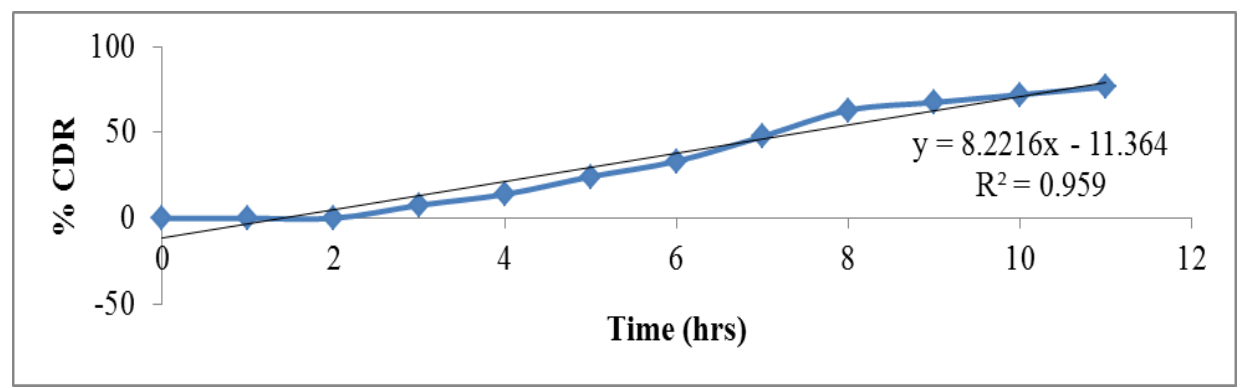

Figure 5: Zero order release kinetics model of enteric coated mucoadhesive tablet containing bael gum (F4)

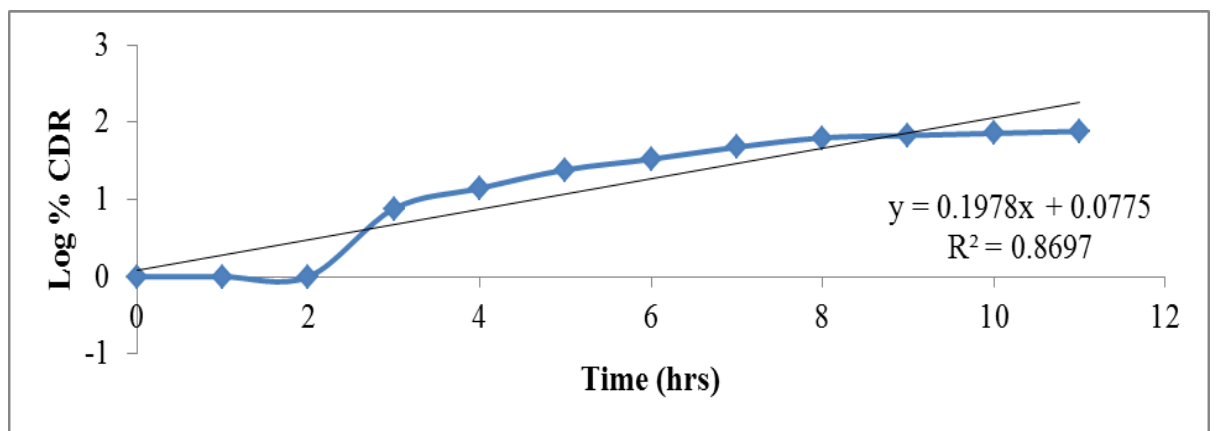

Figure 6: First order release kinetics model of enteric coated mucoadhesive tablet containing bael gum (F4)

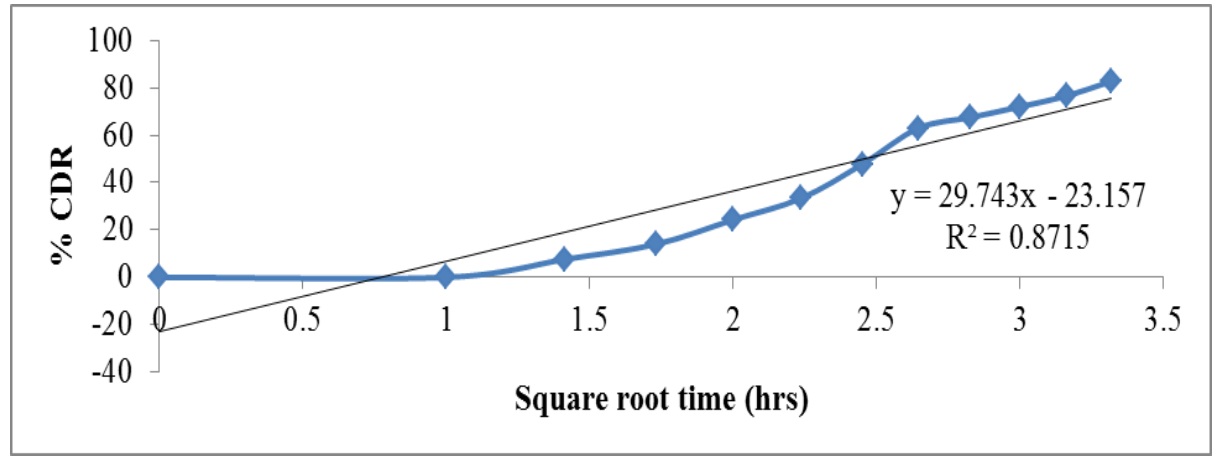

Figure 7: Higuchi model of enteric coated mucoadhesive tablet containing bael gum (F4)

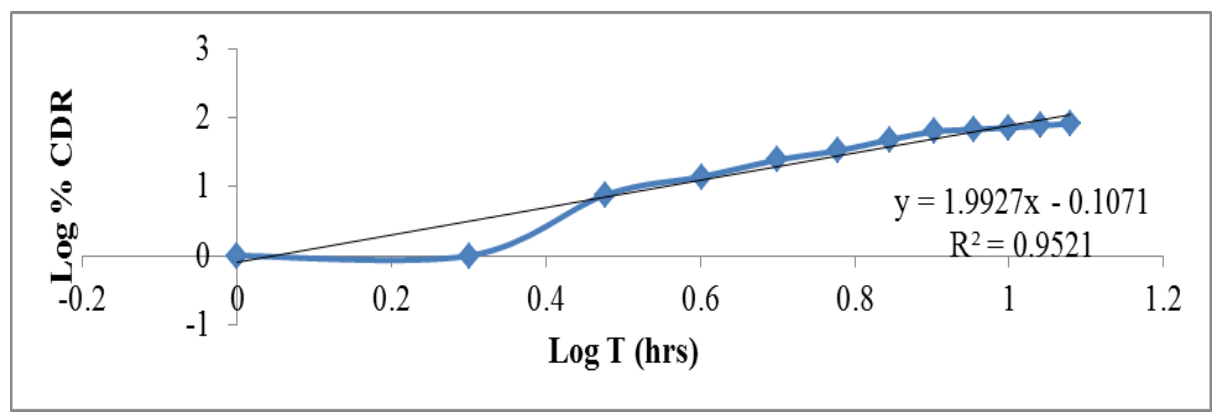

Figure 8: Korsmeyer Peppas model of enteric coated mucoadhesive tablet containing bael gum (F4)

\section{DISCUSSION:}

Thickness of various formulations F1to F6 was found to be in the range of $5.4 \mathrm{~mm}$ to $5.7 \mathrm{~mm}$. And diameter of various formulations was found in the range of $9.4 \mathrm{~mm}$ to $9.6 \mathrm{~mm}$. Parameters are shown in table no. 4.

Hardness of the batches F1 to F6 was found to be in the 6.4 $\mathrm{kg} / \mathrm{cm}^{2}$ to $6.9 \mathrm{~kg} / \mathrm{cm}^{2}$. And \%weight variation of various formulations was found in the range of $-0.006 \%$ to 0.020 $\%$. It seems that weight variation was within the limit. Hardness and weight variation of various batches are shown in table no. 4. As per the obtained result, it can be summarized that the average percentage loss in weight of the formulations $\mathrm{F} 1$ to $\mathrm{F} 6$ was found to be in the range of $0.033344 \%$ to $0.100127 \%$. Drug content of formulations were in the range of $93.043 \%$ to $99.130 \%$. In all the prepared tablets the specified amount of Captopril were found, which indicates the uniformity in drug content shown in the table no. 4 . The tabulated data shows that the surface $\mathrm{pH}$ of the formulations F1 to F6 was found to be in the range of 6.9 to 7.1 . It seems that the surface $\mathrm{pH}$ of all the formulations was within the satisfactory limit. Surface $\mathrm{pH}$ of various batches is shown in table no. 4 .

Portrays of the swelling percentage of all the formulations (F1 to F6) shown in figure 1. All the formulations were showing better swelling properties. The detachment time 
of formulations was shown in table no. 5. Average detachment time of different formulations F1to F6 was in the range of $380 \mathrm{mins}$ to $452 \mathrm{mins}$. And it was suggesting that all the formulations have sufficient mucoadhesive strength to remain intact with gastric mucosa for long time to release the drug in a controlled manner. Detachment time of formulations is shown in table no.5. As per the obtained result, it can be summarized that the mucoadhesive strength of the formulations F1to F6 shows adhesion strength in the range of $22.003 \mathrm{gm}$ to $38.003 \mathrm{gm}$. Mucoadhesive strength and force of adhesion of various formulations were shown in figure no. 2 and 3 .

Formulations F1 to F6 showing release in the range of $86.488 \%$ to $97.186 \%$. The formulation F4 containing bael gum has shows a better drug release of $86.488 \%$ after coating in comparisons to formulations F1to F6 with in 12 hrs. \%Cumulative drug release of F1 to F6 formulations was shown in the figure no. 4.

\section{REFERENCE:}

1. Mote $P B$ et al., "Formulation and Evaluation of Sustained Release Matrix Tablets of Anti-Asthmatic Agent Using Various Polymers" JDDT, 2013, 3(2), 88-92.

2. Lieberman HA, Lachman L and Schwartz JB. Pharmaceutical dosage forms. $2^{\text {nd }}$ ed. Marcel Dekker Inc; 1990. P. 77-124.

3. Johnson JL. Coating technology handbook, Taylor and francis group, 2006. P. 112.1 - 112.3.

4. Jurca T and Vicaş L. Complexes of the ACE Inhibitor Captopril, Farmacia, 2010 58(2), 199-202.

5. Chanda R, Nath LK, Dash S. and Mahapatra SK, "Design and Evaluation of Mucoadhesive Controlled Release Oral Tablets of Terbutaline Sulphate Using Some Natural Materials" IJPST, 2008, 1(1), 15-21.

6. Manivannan R, Senthil BK, Parthiban KG and Jijin C, "Once Daily Intestinal Mucoadhesive Esomeprazole Magnesium Tablet Formulation and In-Vitro Evaluation" J GPT, 2010, (8), 10-18.

7. Goswami DS, Choudhury PK, Goyal SK and Sharma R, "Formulation Design And Optimization of An Enteric Coated

\section{CONCLUSION:}

Delayed sustained release tablet of Captopril was prepared by the wet granulation technique using HPMC K4M, bael gum and chitosan as mucoadhesive polymer. It was concluded that the rate of drug release from all the formulations primarily was good. The coating was done by spraying method using eudragit RL100 as a polymer. The prepared tablet was found to be successful with respect to parameters evaluated such as weight variation, friability, drug content, surface $\mathrm{pH}$, wash off test, mucoadhesive strength and in-vitro drug release study. According to wash-off test the formulation containing bael gum showing better results. According to mucoadhesive strength, F4 (formulation containing bael gum) showing best result among all the formulations. In in-vitro drug release study formulation (F4) containing bael gum showing better control release among all the formulations i.e. $86.488 \%$ in $12 \mathrm{hrs}$.

Sustained Release Mucoadhesive Tablet of Metranidazole" IJPTR, 2010, 2(2), 1269-1275.

8. Mahalaxmi D, Senthil A, Prasad V, Sudhakar B and Mohideen S, "Formulation And Evaluation of Mucoadhesive Buccal Tablets Of Glipizide" IJBP., 2010; 1(2): 100-107.

9. Vaidya VM, Manwar JV, Mahajan NM, and Sakarkar DM, "Design and In-Vitro Evaluation of Mucoadhesive Buccal Tablets of Terbutaline Sulphate" IJPTR, 2009, 1(3), 588-597.

10. Paul Y, Kumar S and Sehrawat R, "Design Development and Characterization of Mucoadhesive Tablets of Atenolol" IJPBS, 2012, 3(1), 383-395.

11. Bhadur S et al., "Physicochemical Characterization and Evaluation of Omeprazole Tablet for Local Action" JPSR, 2009, 1(4), 116-122.

12. Dash S, Murthy PN, Nath L and Chowdhury P, "Kinetic Modeling on Drug Release from Controlled Drug Delivery Systems" APPDR, 2010, 67(3), 217-223. 